\title{
Viscoelastic behaviour and fracture toughness of linear-low-density polyethylene reinforced with synthetic boehmite alumina nanoparticles
}

\author{
D. Pedrazzoli ${ }^{1}$, R. Ceccato $^{1}$, J. Karger-Kocsis ${ }^{2,3}$, A. Pegoretti $^{1 *}$ \\ ${ }^{1}$ University of Trento, Department of Industrial Engineering and INSTM Research Unit, Via Mesiano 77, 38123 Trento, Italy \\ ${ }^{2}$ MTA-BME Research Group for Composite Science and Technology, Muegyetem rkp. 3., H-1111 Budapest, Hungary \\ ${ }^{3}$ Department of Polymer Engineering, Faculty of Mechanical Engineering, Budapest University of Technology and \\ Economics, Múegyetem rkp. 3., H-1111 Budapest, Hungary
}

Received 1 March 2013; accepted in revised form 14 April 2013

\begin{abstract}
Aim of the present study is to investigate how synthetic boehmite alumina (BA) nanoparticles modify the viscoleastic and fracture behaviour of linear low-density polyethylene. Nanocomposites containing up to $8 \mathrm{wt} \%$ of untreated and octyl silane-functionalized BA nanoparticles, were prepared by melt compounding and hot pressing.

The BA nanoparticles were finely and unformly dispersed within the matrix according to scanning electron microscopy inspection. The results of quasi-static tensile tests indicated that nanoparticles can provide a remarkable stiffening effect at a rather low filler content. Short term creep tests showed that creep stability was significatively improved by nanofiller incorporation. Concurrently, both storage and loss moduli were enhanced in all nanocomposites, showing better result for surface treated nanoparticles.

The plane-stress fracture toughness, evaluated by the essential work of fracture approach, manifested a dramatic increase (up to 64\%) with the BA content, with no significant differences among the various types of BA nanoparticles.
\end{abstract}

Keywords: nanocomposites, fracture and fatigue, mechanical properties, thermal properties

\section{Introduction}

Increasing efforts are devoted to the research of thermoplastic nanocomposites exhibiting improved and novel properties. Most of these studies are focused on the investigation of correlations between structural features and mechanical properties. A large body of research has been developed on polar nanofillers (such as silicas, metal oxides, metal salts, layered silicates, etc.) which have been successfully added to thermoplastic matrices in order to improve their thermal, mechanical and rheological performances [1-8]. On the other hand, these nanofillers are generally poorly dispersed in apolar thermoplastics (such as polyolefins), thus limiting the beneficial effects of nanofiller addition on the thermo-mechanical properties. Different strategies have been adopted in order to improve the dispersability of polar nanofillers, such as the direct incorporation of the filler during the in-situ synthesis of the polymer [9], the addition of the filler during melt mixing $[10,11]$ or the dispersion of the filler by solution techniques [12]. However, in order to attain a qualitatively fine dispersion of the nanofiller within the matrix, a surface treatment of the filler should be considered [13-15], or a polymeric compatibilizer should be added during melt mixing [5, 16-19].

Due to its combination of low cost, high chemical resistance and relatively good mechanical proper-

\footnotetext{
${ }^{*}$ Corresponding author, e-mail: alessandro.pegoretti@unitn.it (C) BME-PT
} 
ties, polyethylene is one of the most largely used polyolefin. In particular, linear low-density polyethylene (LLDPE) is widely used for film production in the packaging industry, especially because of its high tear and impact strength [20]. Dorigato et al. [2, 21, 22] studied the effect of various kinds of amorphous silica nanoparticles on the viscoelastic and fracture behaviour of LLDPE based composites. Elastic moduli of the prepared composites resulted to be strictly related to the surface area of the filler rather than by its dimensions. Tensile properties at yield and at break increased with the surface area of the nanofiller and were positively affected by the presence of an organosilane on the surface of the nanoparticles. Furthermore, the application of the essential work of fracture (EWF) approach showed that the introduction of fumed silica nanoparticles produced an evident toughening [22]. Moreover, it has been also proven that the addition of surface treated silica particles to a polypropylene matrix can lead to a certain improvement of the thermo-mechanical properties of the matrix itself and a remarkable increase of the fiber/matrix adhesion when E-glass fibers are added [23].

Boehmite (BA) with chemical composition $\mathrm{AlO}(\mathrm{OH})$ is a quite inexpensive mineral component of the aluminum ore bauxite. It can also be produced synthetically in particulates with different aspect ratios. Their primary particle size is in the range of tens of nanometers. The recent interest for using BA fillers to produce thermoplastic nanocomposites is fuelled by the fact that they can be finely dispersed on nanoscale by both traditional and water-assisted melt compounding techniques [24-30].

The present work aims at investigating the effect of BA addition on the viscoelastic behaviour of LLDPE. Particular emphasis has been devoted to the study of the fracture toughness evaluated by the EWF approach.

\section{Experimental section}

\subsection{Materials and samples preparation}

The matrix used in this work was a Flexirene ${ }^{\circledR}$ CL10 linear low-density polyethylene (MFI at $190^{\circ} \mathrm{C}$ and $2.16 \mathrm{~kg}=2.6 \mathrm{~g} / 10 \mathrm{~min}, M_{\mathrm{n}}=27000 \mathrm{~g} \cdot \mathrm{mol}^{-1}$, density $=0.918 \mathrm{~g} \cdot \mathrm{cm}^{-3}$ ), produced by Versalis S.p.A. (Mantova, Italy) using Ziegler-Natta catalysis and butene as a comonomer $\left(\mathrm{C}_{4}\right.$-LLDPE). This type of linear low density polyethylene, containing antioxidants, is suitable for cast extrusion of thin films with high optical properties.

Two different grades of untreated BA, namely Disperal $^{\circledR} 40$ (BA-D40) and Disperal ${ }^{\circledR} 80$ (BA-D80) (supplied by Sasol GmbH, Hamburg, Germany) were used as fillers. Their nominal primary crystallite sizes are 40 and $72 \mathrm{~nm}$, respectively (Table 1). Moreover, a silane surface treated BA(Disperal ${ }^{\circledR} 40$ octylsilane treated, BA-D40 OS), characterized by the same primary crystallite size as Disperal ${ }^{\circledR} 40$ was also used.

LLDPE chips were used as received while the BA fillers were dried at $80^{\circ} \mathrm{C}$ for $12 \mathrm{~h}$ prior to use. The samples were prepared by melt compounding in a Brabender ${ }^{\circledR}$ Plasti-Corder internal mixer $\left(T=170^{\circ} \mathrm{C}\right.$, $n=50 \mathrm{rpm}, t=15 \mathrm{~min}$ ) followed by compression moulding using a Collin ${ }^{\circledR} \mathrm{P} 200 \mathrm{E}$ hot press $(T=$ $\left.170^{\circ} \mathrm{C}, P=2 \mathrm{MPa}, t=15 \mathrm{~min}\right)$, to shape square plane sheets with a thickness of about $0.5 \mathrm{~mm}$. The filler content was varied between 0 and $8 \mathrm{wt} \%$.

The unfilled matrix was denoted as LLDPE, while the coding of the nanocomposites indicated the matrix, the filler type, and the filler weight amount, as well. For instance, a sample filled with $4 \mathrm{wt} \%$ of Disperal $^{\circledR} 40$ is coded as LLDPE-D40-4.

\subsection{Experimental techniques}

\subsubsection{Filler characterization}

Density measurements were carried out through a helium pycnometer (Micromeritics ${ }^{\circledR}$ Accupyc 1330,

Table 1. Physical properties of BA nanoparticles utilized in this work

\begin{tabular}{|c|c|c|c|c|}
\hline Filler & $\begin{array}{l}\text { Density } \\
{\left[\mathrm{g} \cdot \mathrm{cm}^{-3}\right]}\end{array}$ & $\begin{array}{c}\text { BET surface } \text { area }^{b} \\
{\left[\mathrm{~m}^{2} \cdot \mathrm{g}^{-1}\right]}\end{array}$ & $\begin{array}{c}\text { Particle size d50 }^{\mathrm{b}} \\
{[\mu \mathrm{m}]}\end{array}$ & $\begin{array}{c}\text { Crystallite size }^{\mathrm{c}} \\
\text { [nm] }\end{array}$ \\
\hline BA-D40 & $3.007 \pm 0.004$ & 105.0 & 50 & 38 \\
\hline BA-D40 OS & $3.010 \pm 0.025$ & 105.0 & 50 & 40 \\
\hline BA-D80 & $3.018 \pm 0.004$ & 88.0 & 80 & 72 \\
\hline
\end{tabular}

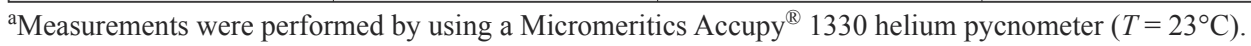

bKhumalo VM, Karger-Kocsis J., Thomann R.: Polyethylene/synthetic boehmite alumina nanocomposites: Structure, thermal and rheological properties. eXPRESS Polymer Letters. 2010, 4(5):264-274.

${ }^{\mathrm{c}}$ Measurements were performed by XRD analyses and applying the Sherrer equation.

Note that BET surface area, primary particle size and crystallite size of BA-D40 OS were assumed to be the same of BA-D40 due to lack of information in the datasheet. 
Norcross USA), at a temperature of $23^{\circ} \mathrm{C}$, in a testing chamber with a volume of $3.5 \mathrm{~cm}^{3}$.

$\mathrm{X}$-Ray diffraction measurements on BA powders were performed by a Rigaku ${ }^{\circledR}$ 3D Max X-ray diffractometer, scanning the samples in a $2 \theta$ range between 3 and $67^{\circ}$, at a $2 \theta$ step of $0.1^{\circ}$. The wavelength of the X-ray source was $0.1541 \mathrm{~nm}$.

\subsubsection{Spectroscopy analyses}

Cryogenic fracture surfaces of unfilled LLDPE and LLDPE nanocomposites were observed at various magnifications by using a Zeiss Supra 40 (Berlin, Germany) field emission scanning electron microscope (FESEM), at an acceleration voltage between 1 and $2 \mathrm{kV}$.

IR spectroscopy was performed on the nanofillers and on $80 \mu \mathrm{m}$ thick nanocomposite films in a wave number interval between 650 and $4000 \mathrm{~cm}^{-1}$, setting a resolution of $2 \mathrm{~cm}^{-1}$ for a total number of 64 co-added scans.

\subsubsection{Diffraction analysis}

$\mathrm{X}$-ray diffraction analysis was performed through a Rigaku $^{\circledR}$ 3D Max powder diffractometer, in BraggBrentano geometry, using $\mathrm{CuK}_{\alpha}$ radiation $(0.1541 \mathrm{~nm})$ and a curved graphite monochromator in the diffracted beam. Typical scans adopted the following parameters: $2 \theta$ range between 3 and $67^{\circ}$, sampling interval $0.1^{\circ}$, counting time $4 \mathrm{~s}$.

\subsubsection{Rheology measurements}

Melt rheology of neat LLDPE and of nanocomposites was analyzed by a Rheoplus MCR 301 rheometer (Anton Paar Physics, Ostfildern, Germany) under controlled strain conditions. The test geometry was cone-plate (cone angle $=1^{\circ}$ ) with a diameter of the plates of $25 \mathrm{~mm}$. Compression molded disks of around $0.6 \mathrm{~mm}$ thickness were placed between the plates at $180^{\circ} \mathrm{C}$. The gap width was set to $0.5 \mathrm{~mm}$ by squeezing the LLDPE disk. Frequency sweep tests were carried out at $180^{\circ} \mathrm{C}$. During the measurement a small amplitude (1\%) oscillatory shear was applied to the samples. The storage and loss shear moduli ( $G^{\prime}$ and $G^{\prime \prime}$, respectively) and the dynamic viscosity $\left|\eta^{*}\right|$ were measured as a function of angular frequency $(\omega)$ in the range $0.01-100 \mathrm{rad} / \mathrm{s}$.

\subsubsection{Thermal analyses}

Differential scanning calorimetry (DSC) tests were carried out by a DSC Q2000 (TA Instruments-
Waters LLC, New Castle, USA) differential scanning calorimeter under a constant nitrogen flow of $50 \mathrm{ml} \cdot \mathrm{min}^{-1}$. Samples were heated up to $200^{\circ} \mathrm{C}$ at a rate of $10^{\circ} \mathrm{C} \cdot \mathrm{min}^{-1}$ and cooled to $0^{\circ} \mathrm{C}$ at a cooling rate of $10^{\circ} \mathrm{C} \cdot \mathrm{min}^{-1}$. A second heating scan was then performed at $10^{\circ} \mathrm{C} \cdot \mathrm{min}^{-1}$. The melting enthalpy of $100 \%$ crystalline polyethylene has been considered equal to $\Delta H^{0}=290 \mathrm{~J} \cdot \mathrm{g}^{-1}$ [31]. The crystallinity $\chi_{\mathrm{c}}$ of nanocomposite samples was estimated by taking the weight fraction of LLDPE in the composites into account. The melting temperatures $T_{\mathrm{m} 1}$ and $T_{\mathrm{m} 2}$ were recorded during the first and second heating scan, respectively. The crystallization enthalpy $\Delta H_{\mathrm{c}}$ was measured by integrating the heat flow curve during the cooling scan.

Thermogravimetric analyses (TGA) were carried out through a Q5000 IR thermogravimetric analyzer (TA Instruments-Waters LLC, New Castle, USA) imposing a temperature ramp between 40 and $700^{\circ} \mathrm{C}$ at a heating rate of $10^{\circ} \mathrm{C} \cdot \mathrm{min}^{-1}$ under a constant nitrogen flow of $25 \mathrm{ml} \cdot \mathrm{min}^{-1}$. The onset of degradation temperature ( $\left.T_{\mathrm{d} \text {,onset }}\right)$ was determined by the point of intersection of the tangents to the two branches of the thermogravimetric curve, while the maximum rate of degradation temperature $\left(T_{\mathrm{d}, \max }\right)$ was determined from the peak maxima in the first derivative of weight loss curve.

\subsubsection{Mechanical tests}

Uniaxial tensile tests were performed with an Instron ${ }^{\circledR} 4502$ (Norwood, USA) tensile machine on samples of at least five ISO 527 type 1BA specimens. The tests were carried out at a crosshead speed of $0.25 \mathrm{~mm} \cdot \mathrm{min}^{-1}$ up to a maximum axial deformation of $1 \%$. The strain was recorded by using a resistance extensometer Instron ${ }^{\circledR}$ model 2620 601 with a gage length of $12.5 \mathrm{~mm}$. In accordance to ISO 527 standard, the elastic modulus was measured as a secant value between deformation levels of 0.05 and $0.25 \%$. Uniaxial tensile properties, such as stress at yield $\left(\sigma_{\mathrm{y}}\right)$, stress at break $\left(\sigma_{\mathrm{b}}\right)$ and strain at break $\left(\varepsilon_{\mathrm{b}}\right)$ were determined at a higher crosshead speed $\left(50 \mathrm{~mm} \cdot \mathrm{min}^{-1}\right)$ without extensometer.

Dynamic mechanical thermal analysis (DMTA) was carried out with a DMA Q800 testing machine (TA Instruments ${ }^{\circledR}$-Waters LLC, New Castle, USA) on rectangular specimens $25 \mathrm{~mm}$ long, $5 \mathrm{~mm}$ wide and $0.5 \mathrm{~mm}$ thick. The samples were analyzed over a temperature range between -130 and $80^{\circ} \mathrm{C}$, imposing a heating rate of $3^{\circ} \mathrm{C} \cdot \mathrm{min}^{-1}$ and a frequency of 
$1 \mathrm{~Hz}$. A preload of $0.2 \mathrm{MPa}$ and a maximum strain of $0.05 \%$ were set for each test. The most important viscoelastic functions $\left(E^{\prime}, E^{\prime \prime}, \tan \delta\right)$ were recorded at different temperatures. By the same apparatus, short term $(3600 \mathrm{~s})$ tensile creep tests at $30^{\circ} \mathrm{C}$ were also performed at a constant applied stress $\left(\sigma_{0}\right)$ of $1 \mathrm{MPa}$ (i.e $10 \%$ of the stress at yield of unfilled LLDPE).

The plane stress fracture toughness of neat LLDPE and nanocomposites was assessed through the essential work of fracture (EWF) method under tensile conditions. According to this approach [32], the total fracture energy $\left(W_{\mathrm{f}}\right)$ spent to bring a precracked body to complete failure can be partitioned into an essential work $\left(W_{\mathrm{e}}\right)$ required in the fracture zone to create new fracture surfaces and a nonessential work $\left(W_{\mathrm{p}}\right)$ dissipated in the outer plastic zone and required to yield the material. It can be easily derived that the essential work of fracture should be proportional to the ligament length $(L)$, whereas the non-essential work of fracture should be proportional to $L^{2}$ see Equation (1):

$W_{\mathrm{f}}=W_{\mathrm{e}}+W_{\mathrm{p}}=w_{\mathrm{f}} L \cdot B=w_{\mathrm{e}} \cdot L \cdot B+w_{\mathrm{p}} \cdot \beta \cdot L^{2} \cdot B$

which can be written as shown by Equation (2):

$w_{\mathrm{f}}=w_{\mathrm{e}}+\beta \cdot w_{\mathrm{p}} \cdot L$

where $B$ is the specimen thickness, $\beta$ is a shape factor, $w_{\mathrm{e}}$ is the specific essential work of fracture, $w_{\mathrm{p}}$ is the specific non-essential work of fracture. The quantities $w_{\mathrm{e}}$ and $\beta \cdot w_{\mathrm{p}}$ are determined by a linear interpolation of a series of experimental data of $w_{\mathrm{f}}$ obtained by testing specimens having different ligament lengths. The quantity $w_{\mathrm{p}}$ can be explicitly deduced for some shapes of the outer plastic zone with known $\beta$ e.g., for circular, elliptical and diamond-type zones $\beta$ is given by $\pi / 4, \pi \cdot h /(4 L)$, and $h /(2 L)$, respectively, where $h$ is the height of the corresponding zone [33].

Furthermore, the specific total work of fracture $\left(w_{\mathrm{f}}\right.$, see Equation (3)) can be divided into a specific work of fracture for yielding $\left(w_{\mathrm{y}}\right)$ and a specific work of necking $\left(w_{\mathrm{n}}\right)[33]$ :

$w_{\mathrm{f}}=w_{\mathrm{y}}+w_{\mathrm{n}}=\left(w_{\mathrm{e}, \mathrm{y}}+\beta^{\prime} \cdot w_{\mathrm{p}, \mathrm{y}} \cdot L\right)+\left(w_{\mathrm{e}, \mathrm{n}}+\beta^{\prime \prime} \cdot w_{\mathrm{p}, \mathrm{n}} \cdot L\right)$

Double-edge-notched-tensile (DENT) specimens (width $30 \mathrm{~mm}$, height $80 \mathrm{~mm}$, thickness $0.5 \mathrm{~mm}$, distance between the grips $50 \mathrm{~mm}$ ) were tested with an Zwick ${ }^{\circledR}$ Z005 tensile machine. At least four tests were conducted for every ligament length, and five different ligament lengths between 5 and $13 \mathrm{~mm}$ were tested at a crosshead speed of $10 \mathrm{~mm} \cdot \mathrm{min}^{-1}$. The notches were prepared by using a home-made apparatus mounting a razor blade, in order to obtain a very sharp crack tip. From SEM images it was possible to estimate an average crack tip radius of less than $20 \mu \mathrm{m}$. The exact ligament lengths were measured with a profile projector with an accuracy of $0.01 \mathrm{~mm}$.

In order to study the fracture behaviour of the material at high strain rate levels, tensile impact tests were carried out with a CEAST ${ }^{\circledR}$ (Norwood, USA) tensile impact instrumented pendulum. A striker of mass $3.65 \mathrm{~kg}$ and initial angular position of $63^{\circ}$ reached an impact speed of $2 \mathrm{~m} \cdot \mathrm{s}^{-1}$ and a total impact energy of 7.3 J. Specific tensile energy to break (TEB) was obtained by Equation (4):

$T E B=\frac{1}{A}\left[V_{0} \int_{0}^{\mathrm{tr}} F \mathrm{dt}-\frac{1}{2 m}\left(\int_{0}^{\mathrm{tr}} F \mathrm{dt}\right)^{2}\right]$

where $A$ is the cross section of the specimen, $m$ is the striker mass and $V_{0}$ is the impact speed.

\section{Results and discussion \\ 3.1. Morphology}

SEM pictures taken from the cryogenic surfaces of LLDPE composites with $4 \mathrm{wt} \% \mathrm{BA}$ are represented in Figure 1. The nanofiller appears quite homogeneously dispersed in the case of LLDPE-D40-4 composite, altough some agglomerates are clearly recognizable. On the other hand, the silane coupling agent present on the surface of BA D40 OS nanoparticles does not seem to affect the filler dispersion in the polymer matrix (Figure 1b). Similar finding was recently reported on the BA dispersion in poly( $\varepsilon$-caprolactone) [34]. As already observed by Brostow et al. [35], although the dispersion is not affected by the surface treatment of BA nanoparticles, a better polymer-filler interaction takes place due to replacement of hydroxide surface groups of the nanoparticles with organic ones. The hypothesis of an improved adhesion is consistent with the increment of the mechanical performance as reported later. In the case of LLDPE-D40 OS nanocomposites, wetting of the particles by the polymer matrix is clearly improved by the coupling treatment, making the interface between two phases 


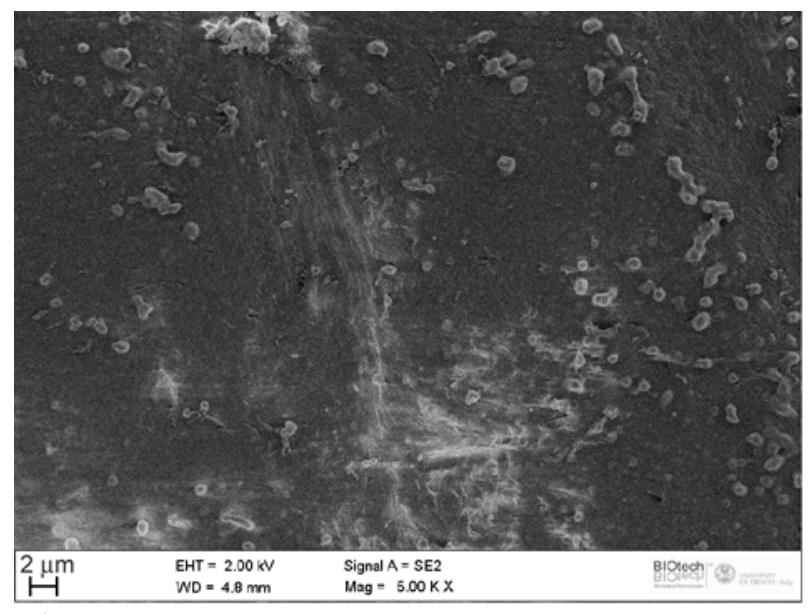

a)

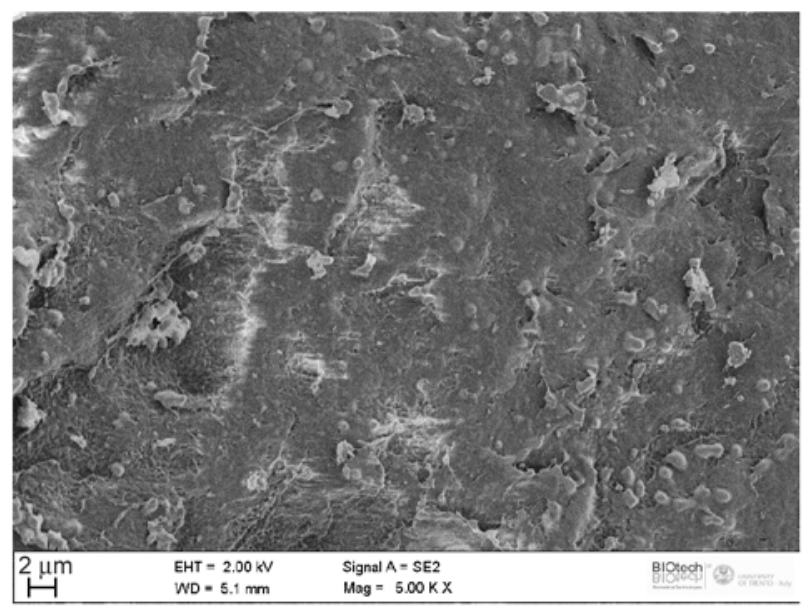

b)

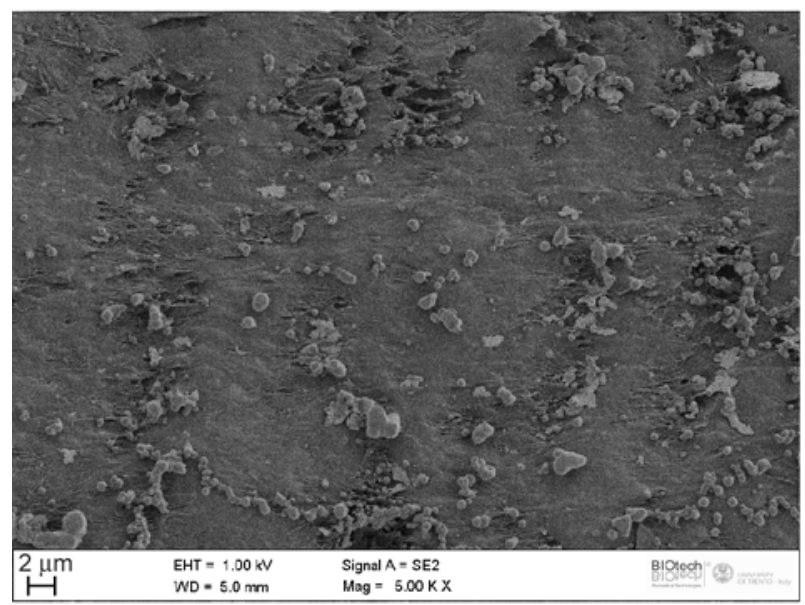

c)

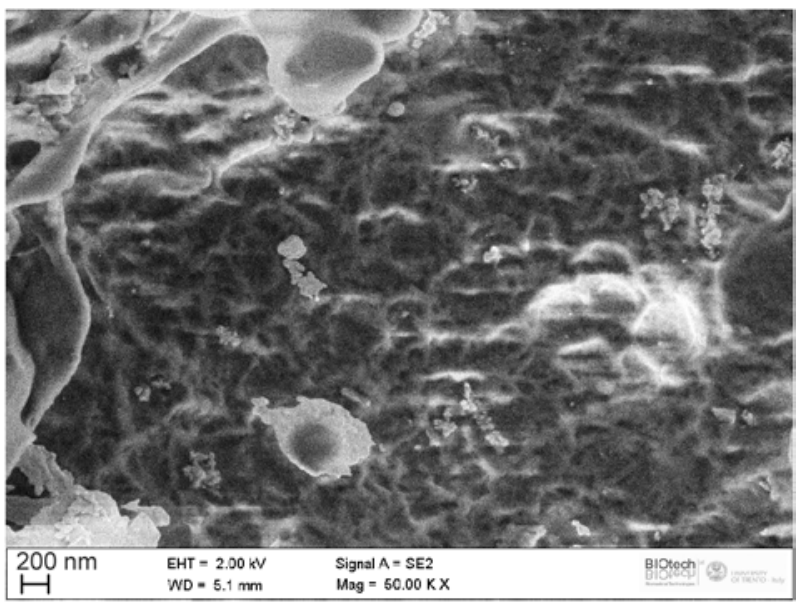

d)

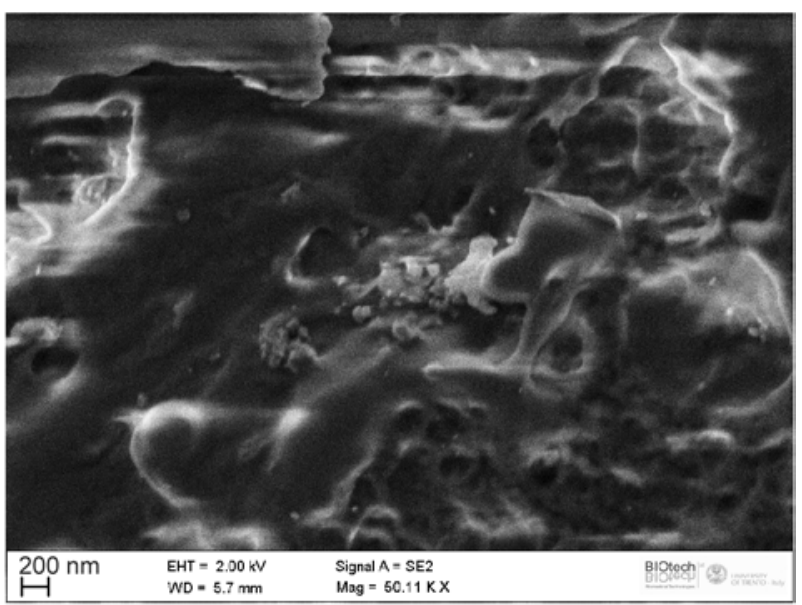

e)

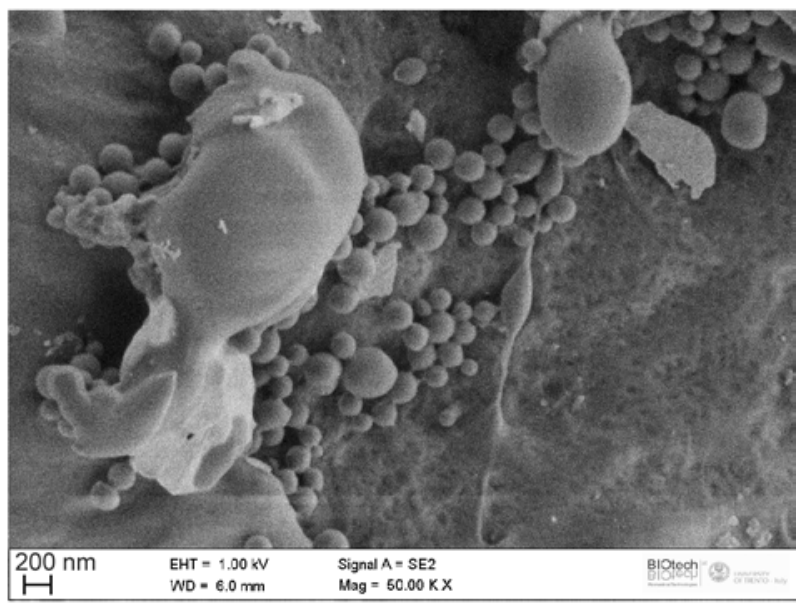

f)

Figure 1. SEM image of the fracture surface of (a, d) LLDPE-D40-4, (b, e) LLDPE-D40 OS-4 and (c, f) LLDPE-D80-4 taken at $5 \mathrm{k} \times(\mathrm{a}, \mathrm{b}, \mathrm{c})$ and $50 \mathrm{k} \times(\mathrm{d}, \mathrm{e}, \mathrm{f})$

almost undistinguishable. The enhancement of the interfacial adhesion can be explained by a decrease in surface energy of the filler with silane coupling agents, that leads to a better compatibility with the apolar LLDPE matrix. SEM pictures taken at higher magnification confirm the presence of both aggregates and agglomerates within the matrix (Figure 1d-1f). In particular, the aggregates of BA give perfectly spherical submicronic particles in the case of LLDPE-D80-4 composite (Figure 1f). As reported by Droval, this is probably due to a memory form effect coming from the aerosol droplets before drying, resulting in each particle considered as a highly concentrated nanocrystallites boehmite aggregates linked together through a water-rich amorphous phase [36]. 


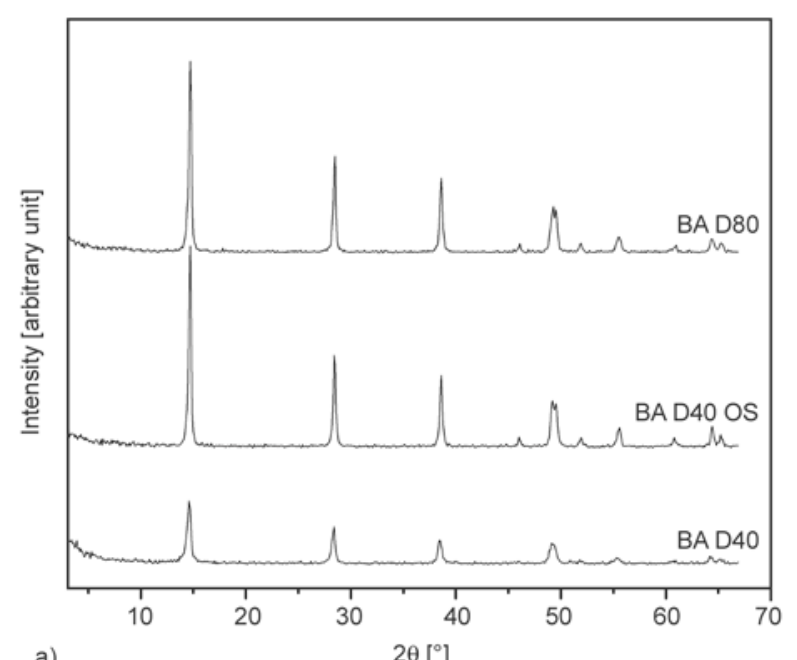

a)

Figure 2. XRD diffractogram of (a) BA nanopowders and (b)

The XRD diffractograms of BA nanopowders and LLDPE nanocomposites are given in Figure 2a and $2 \mathrm{~b}$, respectively. In the X-ray diffractograms of BA nanopowders, the peaks ( $h k l$ plan) at $2 \theta=14.7^{\circ}$ $(020), 2 \theta=28.4^{\circ}(120), 2 \theta=38.7^{\circ}(031), 2 \theta=49.2^{\circ}$ (200), $2 \theta=55.5^{\circ}(151)$ indicate the presence of the typical orthorhombic crystalline form of BA. The average crystallite size, calculated by the Scherrer's equation [37], is about 38,40 and $72 \mathrm{~nm}$ for BA-D40, BA-D40 OS and BA-D80, respectively, in good accordance to the data reported in the material datasheet [26]. According to XRD diffractograms of LLDPE nanocomposites, the intensity of the signals of all peaks increases with the nanofiller amount. Furthermore, for a given filler content, a stronger signal was found for LLDPE-D40 OS-x nanocomposites with respect to LLDPE-D40-x and LLDPED80-x. Most likely, the surface functionalization

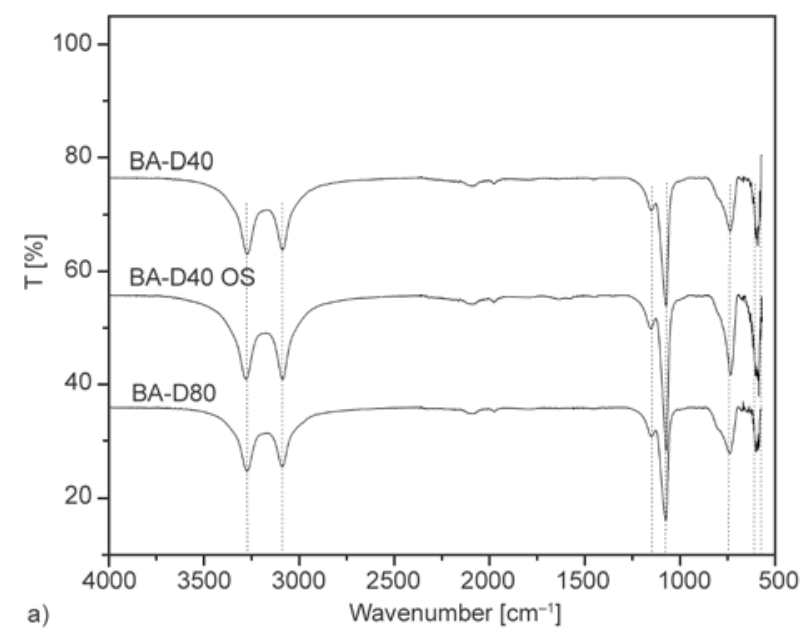

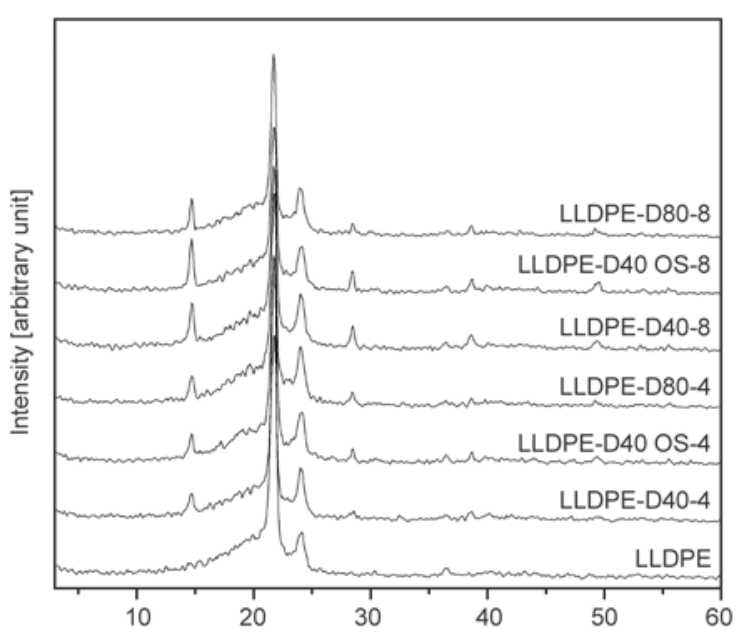

b)

$2 \theta\left[{ }^{\circ}\right]$ induced a higher BA crystallinity with respect to untreated BA, or BA for silane modification was taken from another production batch.

The IR spectra of BA nanopowders correspond to those reported for boehmite in the literature [28, 38]. The $\mathrm{OH}$ stretching $\left(v_{\mathrm{OH}}\right)$ bands are at 3290 and $3091 \mathrm{~cm}^{-1}$, while $\mathrm{OH}$ bending $\left(\delta_{\mathrm{OH}}\right)$ appears at 1151 and $1077 \mathrm{~cm}^{-1}$, the $\gamma_{\mathrm{OH}}$ band is at $751 \mathrm{~cm}^{-1}$, symmetrical and asymmetrical Al-O bonds stretching are at 638 and $529 \mathrm{~cm}^{-1}$ (Figure 3a).

Representative IR spectra of neat LLDPE, LLDPED40-4, LLDPE-D40 OS-4 and LLDPE-D80-4 nanocomposites are compared in Figure 3b. All the spectra of LLDPE-BA nanocomposites are similar with marginal differences in intensity due to the different BA crystallite size. Furthermore, only slight differences are attributable to BA surface functionalization. In particular, formation of small peaks is

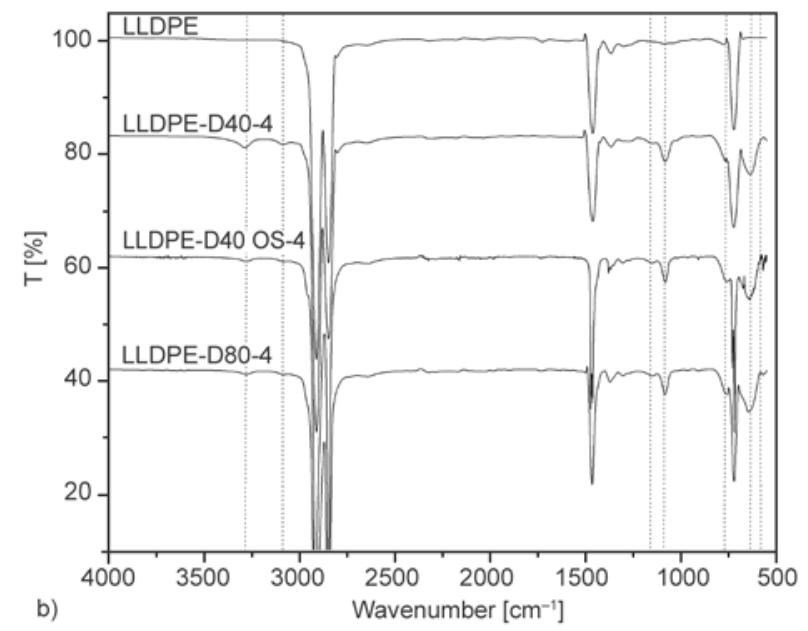

Figure 3. FTIR spectra of (a) BA nanopowders in comparison and (b) LLDPE and LLDPE-BA-4 nanocomposites 
observed in the $800-1700 \mathrm{~cm}^{-1}$ region, which are commonly referred to the presence of silane coupling agents [39].

\subsection{Rheological behavior}

The effect of the filler addition on the isothermal frequency dependence of the dynamic shear storage modulus $\left(G^{\prime}\right)$ and complex viscosity $\left(\left|\eta^{*}\right|\right)$ is reported in Figure 4a for unfilled LLDPE and LLDPE composites filled with $4 \mathrm{wt} \% \mathrm{BA}$. A general decrease in both $G^{\prime}$ and $\left|\eta^{*}\right|$ can be detected for all LLDPE-BA nanocomposites over the whole frequency range. Furthermore, a similar decrease of both $G^{\prime}$ and $\left|\eta^{*}\right|$ is also recorded in the case of composites filled with $8 \mathrm{wt} \%$ BA (Figure 4b). Noteworthy, the lowering in viscosity is very beneficial for the material processing. For the sake of completeness, some instabilities of the samples are observed at low frequencies, mainly regarding the determination of $G^{\prime}$ values. This experimental drawback probably occurs due to the adopted cone-plate configuration.

Incorporation of nanofillers in thermoplastics is generally associated to a marked increase in the melt viscosity, at least in the range of low frequencies. Furthermore, a significative enhancement in $G^{\prime}$ is generally observed. These changes are usually assigned to a pseudo solid-like transition caused by the dispersed nanoparticles [40-46]. Nevertheless, the lowering of both $\left|\eta^{*}\right|$ and $G^{\prime}$ by BA addition to LLDPE contradicts such general trend. It is interesting to observe that Khumalo et al. [26] reported the same rheological behaviour for polyethylene/ synthetic boehmite alumina nanocomposites. In particular, a decrease in both $G^{\prime}$ and $\left|\eta^{*}\right|$ was recorded for LDPE-BA and HDPE-BA nanocomposites with

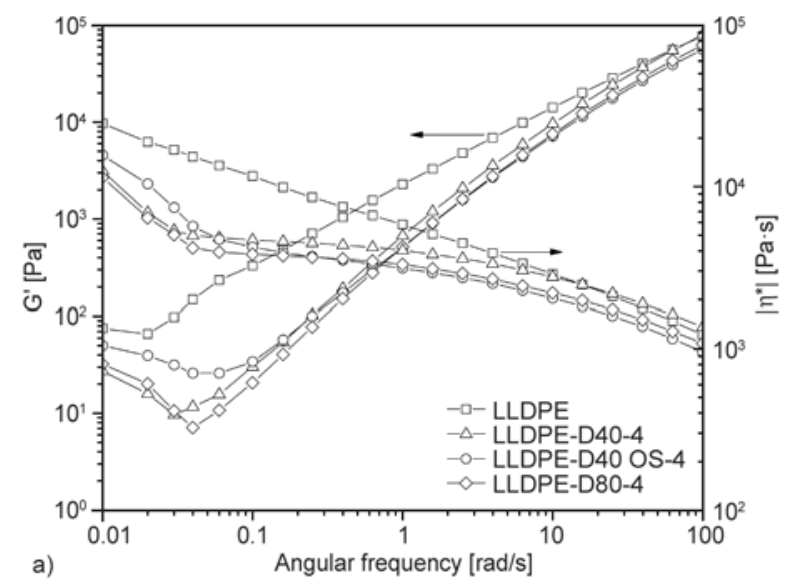

respect to the neat matrices. Also Blaszczak et al. [47] studied the rheological beha€iour of LDPE-BA nanocomposite and found that the addition of BA produces a decrease in $\left|\eta^{*}\right|$ compared to that of unfilled LDPE. A possible explanation is based on the fact that, as a result of good adhesion between the polymer matrix and the mineral filler, the polymer melt with filler flows more uniformly, thus at a lower viscosity despite adding solid filler [47]. Moreover, since LLDPE is a highly branched polymer whose chains would tend to get entangled, apparently even poorly bonded plain BA particles fill in the spaces between chain branches and enable an easier flow.

\subsection{Thermal properties}

As evidenced by DSC analysis, the addition of BA produces a moderate increase of the crystallization temperature for all kinds of boehmite, but no particular dependence of nucleating effect on the BA type is evidenced (Table 2). However, the crystallization peak temperature seems to approach a plateau for boehmite content as high as $4 \mathrm{wt} \%$. The nucleating effect of boehmite was already reported in previous papers for polyethylenes [26] and poplypropylene [27], showing a different nucleating efficiency depending on the crystallite size of boehmite nanofiller.

Concurrently, the melting temperature recorded during the second scan $\left(T_{\mathrm{m} 2}\right)$ is slightly higher for LLDPE nanocomposites, while the crystallinity $\left(\chi_{\mathrm{c}}\right)$ does not seem to have a direct correlation with the nanofiller addition.

The thermal resistance parameters as detected by TGA measurements are also reported in Table 3.

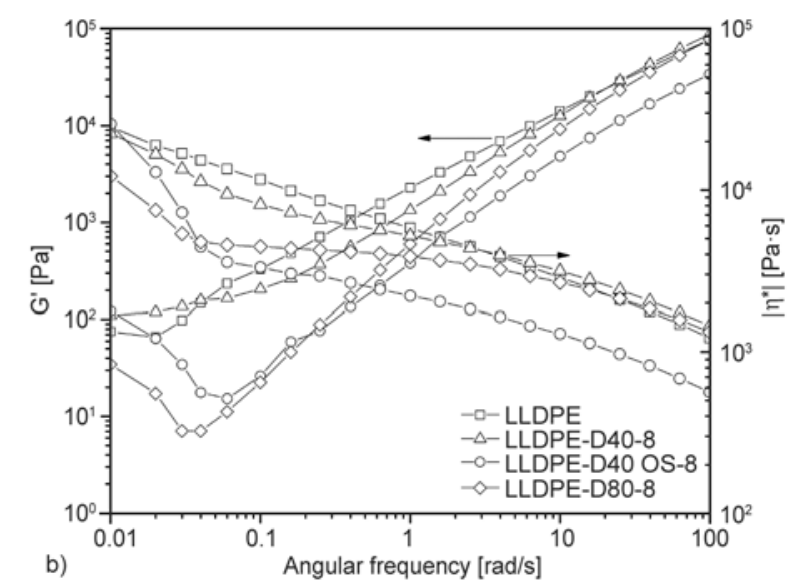

Figure 4. Complex viscosity $\left|\eta^{*}\right|$ and storage modulus $\left(G^{\prime}\right)$ with respect to angular frequency ( $\omega$ ) for (a) LLDPE and LLDPE-BA-4 nanocomposites and (b) LLDPE and LLDPE-BA-8 nanocomposites 
Table 2. Melting and crystallization characteristics of unfilled LLDPE and relative nanocomposites from DSC measurements

\begin{tabular}{|l|c|c|c|c|c|c|}
\hline \multicolumn{1}{|c|}{ Sample } & $\begin{array}{c}\mathbf{T}_{\mathbf{m} 1} \\
{\left[{ }^{\circ} \mathbf{C}\right]}\end{array}$ & $\begin{array}{c}\Delta \mathbf{H}_{\mathbf{m} 1}[\mathbf{J} / \mathbf{g}] \\
\left(\chi_{\mathbf{m} 1}[\mathbf{\%}]\right)\end{array}$ & $\begin{array}{c}\mathbf{T}_{\mathbf{c}} \\
{\left[{ }^{\circ} \mathbf{C}\right]}\end{array}$ & $\begin{array}{c}\Delta \mathbf{H}_{\mathbf{c}}[\mathbf{J} / \mathbf{g}] \\
\left(\chi_{\mathbf{c}}[\mathbf{\%}]\right)\end{array}$ & $\begin{array}{c}\mathbf{T}_{\mathbf{m} 2} \\
{\left[{ }^{\circ} \mathbf{C}\right]}\end{array}$ & $\begin{array}{c}\Delta \mathbf{H}_{\mathbf{m} 2}[\mathbf{J} / \mathbf{g}] \\
\left(\chi_{\mathbf{m} 2}[\mathbf{\%}]\right)\end{array}$ \\
\hline LLDPE & 118.0 & $\begin{array}{c}102.4 \\
(35.3)\end{array}$ & 104.2 & $\begin{array}{c}98.4 \\
(33.9)\end{array}$ & 117.5 & $\begin{array}{c}98.4 \\
(33.9)\end{array}$ \\
\hline LLDPE-D40-1 & 119.5 & $\begin{array}{c}100.8 \\
(35.1)\end{array}$ & 111.1 & $\begin{array}{c}100.3 \\
(34.9)\end{array}$ & 121.3 & $\begin{array}{c}100.6 \\
(35.0)\end{array}$ \\
\hline LLDPE-D40-4 & 121.0 & $\begin{array}{c}102.8 \\
(36.9)\end{array}$ & 111.7 & $\begin{array}{c}98.5 \\
(35.4)\end{array}$ & 120.8 & $\begin{array}{c}98.8 \\
(35.5)\end{array}$ \\
\hline LLDPE-D40-8 & 120.9 & $\begin{array}{c}98.5 \\
(36.9)\end{array}$ & 111.2 & $\begin{array}{c}94.5 \\
(35.4)\end{array}$ & 120.8 & $\begin{array}{c}95.2 \\
(35.7)\end{array}$ \\
\hline LLDPE-D40 OS-1 & 118.9 & $\begin{array}{c}100.4 \\
(35.0)\end{array}$ & 104.7 & $\begin{array}{c}99.3 \\
(34.6)\end{array}$ & 118.1 & $\begin{array}{c}99.9 \\
(34.8)\end{array}$ \\
\hline LLDPE-D40 OS-4 & 121.1 & $\begin{array}{c}101.2 \\
(36.4)\end{array}$ & 111.9 & $\begin{array}{c}99.9 \\
(35.9)\end{array}$ & 119.1 & $\begin{array}{c}100.4 \\
(36.1)\end{array}$ \\
\hline LLDPE-D40 OS-8 & 121.0 & $\begin{array}{c}98.1 \\
(36.8)\end{array}$ & 111.2 & $\begin{array}{c}94.2 \\
(35.3)\end{array}$ & 119.1 & $\begin{array}{c}94.7 \\
(35.5)\end{array}$ \\
\hline LLDPE-D80-1 & 120.6 & $\begin{array}{c}103.2 \\
(35.9)\end{array}$ & 110.4 & $\begin{array}{c}98.6 \\
(34.3)\end{array}$ & 119.3 & $\begin{array}{c}98.6 \\
(34.3)\end{array}$ \\
\hline LLDPE-D80-4 & 121.1 & $\begin{array}{c}101.2 \\
(36.4)\end{array}$ & 111.4 & $\begin{array}{c}99.1 \\
(35.6)\end{array}$ & 121.2 & $\begin{array}{c}99.5 \\
(35.7)\end{array}$ \\
\hline LLDPE-D80-8 & 120.3 & $\begin{array}{c}98.1 \\
(36.8)\end{array}$ & 110.5 & $\begin{array}{c}94.6 \\
(35.5)\end{array}$ & 121.1 & $\begin{array}{c}94.9 \\
(35.6)\end{array}$ \\
\hline
\end{tabular}

Table 3. TGA parameters on unfilled LLDPE and relative nanocomposites

\begin{tabular}{|l|c|c|c|}
\hline \multicolumn{1}{|c|}{ Sample } & $\begin{array}{c}\mathbf{T}_{\mathbf{d}, \text { onset }} \\
{\left[{ }^{\circ} \mathbf{C}\right]}\end{array}$ & $\begin{array}{c}\mathbf{T}_{\mathbf{d}, \mathbf{m a x}} \\
{\left[{ }^{\circ} \mathbf{C}\right]}\end{array}$ & $\begin{array}{c}\text { Char } \\
{[\mathbf{\%}]}\end{array}$ \\
\hline LLDPE & 457.0 & 477.1 & 0.3 \\
\hline LLDPE-D40-1 & 459.9 & 477.3 & 2.7 \\
\hline LLDPE-D40-4 & 461.7 & 479.7 & 3.3 \\
\hline LLDPE-D40-8 & 463.6 & 481.4 & 7.4 \\
\hline LLDPE-D40 OS-1 & 459.1 & 478.3 & 2.2 \\
\hline LLDPE-D40 OS-4 & 459.7 & 478.4 & 3.2 \\
\hline LLDPE-D40 OS-8 & 461.5 & 480.1 & 8.2 \\
\hline LLDPE-D80-1 & 460.7 & 480.0 & 2.1 \\
\hline LLDPE-D80-4 & 461.0 & 480.7 & 3.8 \\
\hline LLDPE-D80-8 & 462.1 & 480.3 & 7.7 \\
\hline
\end{tabular}

When considering LLDPE-boehmite nanocomposites, both $T_{\mathrm{d} \text {,onset }}$ and $T_{\mathrm{d} \text {,max }}$ markedly increase with the filler content, showing a slightly higher efficiency in LLDPE-D80 samples. Improved thermal and thermo-oxidative stability due to the addition of
BA has been already reported for polyethylenes (PEs) [26] and polypropylene (PP) [27, 28]. Nevertheless, future research is required in order to clarify the mechanism of improvement of thermal and thermo-oxidative stability in polyolefines by BA incorporation.

\subsection{Tensile mechanical properties and impact strength}

As reported in Table 4, the addition of BA nanoparticles produces a significant increase of the elastic modulus of the LLDPE matrix, reaching an improvement of $69 \%$ for systems filled with $8 w t \%$ of BA D40, compared to unfilled LLDPE.

The stiffening effect induced by nanofiller incorporation is most often attributed to the formation of a rigid interphase between the matrix and the particles. Nevertheless, it has also been recently pro-

Table 4. Quasi-static tensile properties at yield and at break and tensile energy to break (TEB)

\begin{tabular}{|l|c|c|c|c|c|}
\hline \multicolumn{1}{|c|}{ Sample } & $\begin{array}{c}\text { Tensile modulus } \\
{[\mathbf{M P a}]}\end{array}$ & $\begin{array}{c}\text { Tensile strength at yield } \\
{[\mathbf{M P a}]}\end{array}$ & $\begin{array}{c}\text { Tensile strength at break } \\
{[\mathbf{M P a}]}\end{array}$ & $\begin{array}{c}\text { Elongation at break } \\
{[\%]}\end{array}$ & $\begin{array}{c}\text { TEB } \\
{\left[\mathbf{J} / \mathbf{m m}^{\mathbf{2}}\right]}\end{array}$ \\
\hline LLDPE & $200 \pm 6$ & $11.7 \pm 0.2$ & $21.6 \pm 1.0$ & $1390 \pm 91$ & $0.63 \pm 0.08$ \\
\hline LLDPE-D40-1 & $218 \pm 13$ & $11.8 \pm 0.1$ & $19.6 \pm 0.4$ & $1259 \pm 40$ & $0.63 \pm 0.07$ \\
\hline LLDPE-D40-4 & $262 \pm 13$ & $12.2 \pm 0.4$ & $16.8 \pm 0.5$ & $1124 \pm 69$ & $0.69 \pm 0.11$ \\
\hline LLDPE-D40-8 & $337 \pm 12$ & $12.3 \pm 0.4$ & $15.1 \pm 1.1$ & $964 \pm 41$ & $0.70 \pm 0.06$ \\
\hline LLDPE-D40 OS-1 & $250 \pm 18$ & $11.3 \pm 0.2$ & $22.1 \pm 0.9$ & $1330 \pm 33$ & $0.73 \pm 0.05$ \\
\hline LLDPE-D40 OS-4 & $279 \pm 22$ & $12.9 \pm 0.2$ & $21.1 \pm 0.6$ & $1249 \pm 32$ & $0.84 \pm 0.07$ \\
\hline LLDPE-D40 OS-8 & $306 \pm 10$ & $13.4 \pm 0.2$ & $19.8 \pm 0.3$ & $1040 \pm 35$ & $0.87 \pm 0.11$ \\
\hline LLDPE-D80-1 & $218 \pm 17$ & $12.1 \pm 0.3$ & $22.8 \pm 0.4$ & $1336 \pm 38$ & $0.63 \pm 0.05$ \\
\hline LLDPE-D80-4 & $246 \pm 10$ & $12.4 \pm 0.2$ & $19.4 \pm 0.4$ & $1135 \pm 54$ & $0.93 \pm 0.09$ \\
\hline LLDPE-D80-8 & $302 \pm 19$ & $13.3 \pm 0.1$ & $19.7 \pm 1.3$ & $1043 \pm 102$ & $0.90 \pm 0.08$ \\
\hline
\end{tabular}


posed that nanoparticles aggregation can be another mechanism responsible for stiffness increase in polymer nanocomposites. A new approach developed by Dorigato et al. [21, 48] was adopted in order to model the elastic properties of LLDPE-BA nanocomposites taking into account the stiffening effect provided by rigid nanoparticles forming primary aggregates, with the hypothesis that part of the polymer matrix is mechanically constrained within the aggregates. In order to implement the model, the Poisson's ratio of matrix and filler were chosen as 0.44 and 0.23 , respectively, while the elastic modulus of BA was considered equal to $385 \mathrm{GPa}$ in according to literature data [49].

The relative elastic modulus of the LLDPE-BA composites is plotted in Figure 5 as a function of the filler volume fraction, along with the fitting curves generated by the adopted model. It can be noticed that the proposed model can predict quite well the elastic modulus of LLDPE-D40-x and LLDPE-D80-x composites over the whole range of filler concentration. Furthermore, the significative increase of the elastic modulus detected for nanocomposites is associated to enhanced $\alpha$ values, which indicates the fraction of matrix constrained by nanoparticles. As already noticed by Dorigato et al. [20] when applying the model to the case of LLDPE filled with fumed silica nanoparticles, there exists an apparent correlation between the $\alpha$ parameter and filler surface area (Table 1). Indeed, the smaller the particle, the higher the surface area and the

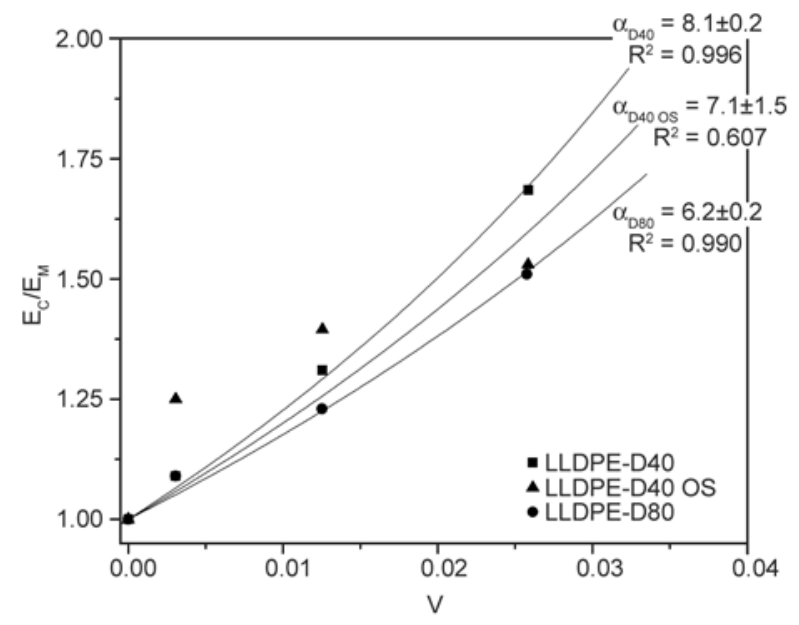

Figure 5. Relative elastic modulus of LLDPE-BA nanocomposites as a function of the filler volume content, with fitting of experimental data in according to the model proposed by Dorigato et al. [21] (continuous line). Note that the error bars of data are not represented for clarity reasons. stronger the propensity to agglomerate, leading to more extensive primary aggregates formed during manufacturing of finer BA filler.

On the other hand, the proposed model does not satisfactory fit the case of LLDPE-D40 OS-x systems, probably due to a better polymer-filler interaction which produces superior interface properties especially at low nanofiller contents. As already observed from SEM micrographs, the surface functionalization of filler does not significatively affect the filler dispersion but improves the interface properties between matrix and filler.

If the ultimate mechanical properties are considered, it can be observed that the yield stress increases proportionally to the filler content while the stress at break decreases for all kinds of BA nanocomposites, probably because of the filler agglomeration and stronger interaction [16]. For the same reason the elongation at break of nanocomposite is lower than that of neat LLDPE. A similar behavior was reported by Khumalo for the tensile yield and strength of LDPE/BA nanocomposites [51]. Both yield stress and stress at break are slightly higher in LLDPE-D40 OS-x and LLDPE-D80-x samples with respect to LLDPE-D40-x.

When the load is applied at high speed through tensile impact tests, the introduction of BA nanoparticles leads to an interesting increase of the tensile energy at break (TEB). The toughening effect is more intense as the nanoparticles are surface functionalized, in accordance with the conclusions reached under quasi-static tensile loading (Table 4). While the presence of an organic modifier on the surface of the nanoparticles seems to not affect the tensile properties at break under quasi-static conditions, tensile energy at break under impact test is remarkably improved in the case of BA40 OS filled nanocomposites. Rong et al. [52, 53] and Wu et al. [54] already found that the addition of small amount of modified nanoparticles $\left(\mathrm{SiO}_{2}\right.$ or $\left.\mathrm{CaCO}_{3}\right)$ could improve the fracture toughness of polypropylene more effectively than the untreated ones, probably due to a better filler/matrix interaction which produces a delaying the shear yielding of the matrix and favours the filler-matrix load transfer mechanism.

Furthermore, the addition of BA D80 and BA D40 OS produces a stronger enhancement in TEB than that of BA D40. This can be attributed to the higher 
yield stress and stress at break measured for the former samples with respect to the latter ones.

\subsection{Viscoelastic behaviour}

In Figure 6 the isothermal creep compliance of unfilled LLDPE and its nanocomposites containing $4 \mathrm{wt} \% \mathrm{BA}$, under a constant load of $1 \mathrm{MPa}$ and at

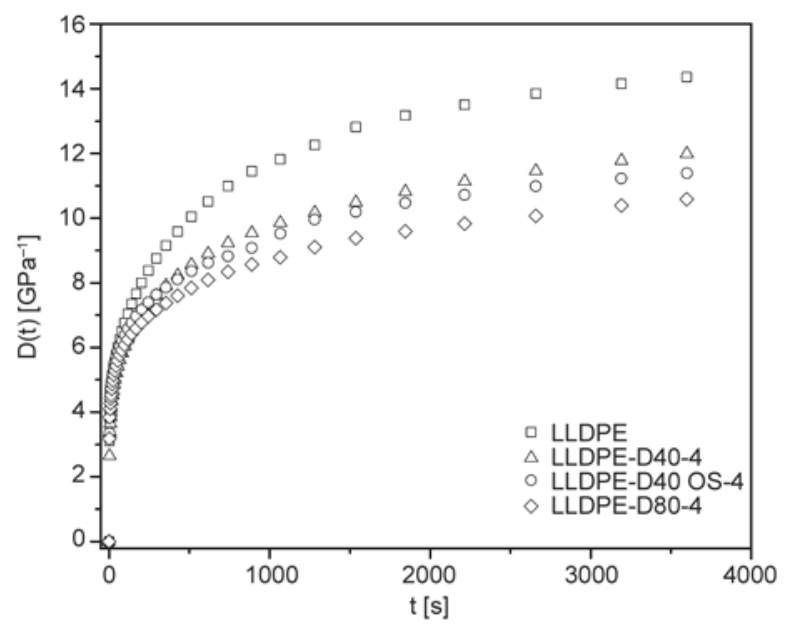

Figure 6. Creep compliance $(D(t))$ of LLDPE and LLDPEBA-4 nanocomposites $\left(T=30^{\circ} \mathrm{C}, \sigma_{0}=1 \mathrm{MPa}\right)$

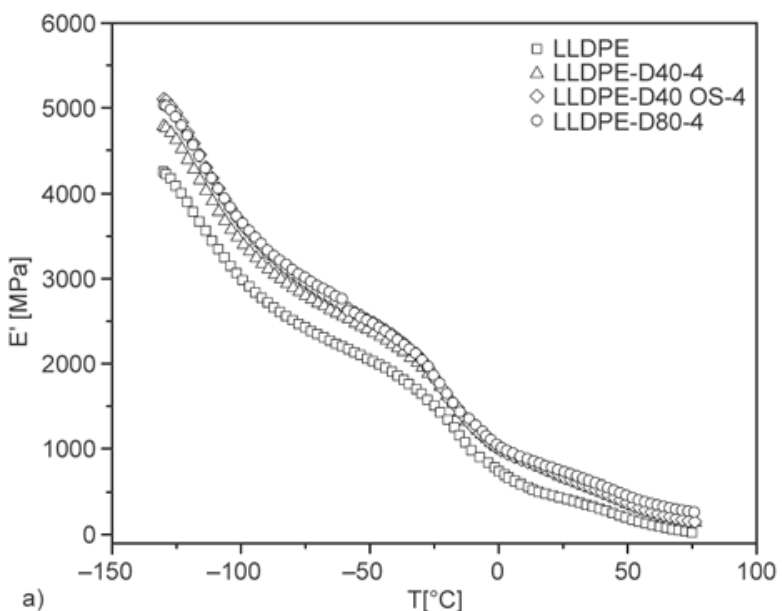

$30^{\circ} \mathrm{C}$, is reported, while in Table 5 the elastic $\left(D_{\mathrm{e}}\right)$ viscoelastic and total components of the creep compliance after $2000 \mathrm{~s}\left(D_{\mathrm{ve} 2000}\right.$ and $D_{\mathrm{t} 2000}$, respectively) are summarized. The introduction of BA nanoparticles leads to a significant improvement of the creep stability of the material. It is generally believed that nanoparticles can effectively restrict the motion of polymer chains, influencing the stress transfer at a nanoscale, with positive effects on the creep stability of the material [55]. The addition of BA-D40 OS nanoparticles provides further creep reduction compared to the untreated one. This is probably due to the better restriction of molecular chains during the viscoelastic flow, affected by the BA surface functionalization.

The dynamic-mechanical response of LLDPE is also markedly affected by the addition of BA nanoparticles. The storage modulus $\left(E^{\prime}\right)$ increases significantly as the BA content increases, probably due to the restrictions of the molecular chains motion (Table 5), thus indicating that the incorporation of BA nanoparticles remarkably enhances stiffness

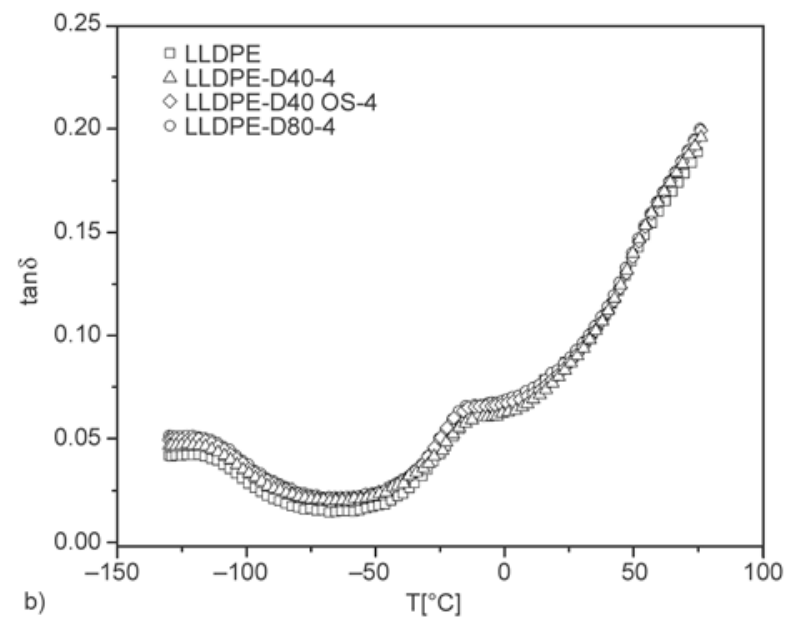

Figure 7. Dynamic mechanical properties of unfilled LLDPE and relative nanocomposites $(f=1 \mathrm{~Hz})$ : (a) Storage modulus $\left(E^{\prime}\right)$ and (b) Loss tangent $(\tan \delta)$

Table 5. Creep compliance data and dynamic mechanical properties of LLDPE and relative nanocomposites $(f=1 \mathrm{~Hz})$

\begin{tabular}{|c|c|c|c|c|c|c|c|}
\hline Sample & $\begin{array}{c}\mathrm{D}_{\mathrm{e}} \\
{\left[\mathrm{GPa}^{-1}\right]}\end{array}$ & $\begin{array}{c}D_{\text {ve2000 }} \\
{\left[\mathrm{GPa}^{-1}\right]}\end{array}$ & $\begin{array}{c}D_{t 2000} \\
{\left[\mathrm{GPa}^{-1}\right]}\end{array}$ & $\begin{array}{c}\mathbf{E}^{\prime}\left(-130^{\circ} \mathrm{C}\right) \\
{[\mathrm{MPa}]}\end{array}$ & $\begin{array}{c}\mathbf{E}^{\prime}\left(\mathbf{2 3}^{\circ} \mathrm{C}\right) \\
{[\mathrm{MPa}]}\end{array}$ & $\begin{array}{c}\mathbf{E}^{\prime \prime}\left(23^{\circ} \mathrm{C}\right) \\
{[\mathrm{MPa}]}\end{array}$ & $\begin{array}{c}\mathbf{T}_{\mathbf{g}} \\
{\left[{ }^{\circ} \mathbf{C}\right]}\end{array}$ \\
\hline LLDPE & 5.96 & 7.39 & 13.35 & 4236 & 416 & 26.0 & -110.5 \\
\hline LLDPE-D40-1 & 5.91 & 5.74 & 11.65 & 4448 & 590 & 50.8 & -108.2 \\
\hline LLDPE-D40-4 & 5.72 & 5.30 & 11.02 & 4784 & 684 & 56.8 & -104.7 \\
\hline LLDPE-D40-8 & 5.44 & 4.80 & 10.24 & 4942 & 686 & 61.7 & -103.4 \\
\hline LLDPE-D40 OS-1 & 5.86 & 5.65 & 11.51 & 4429 & 540 & 48.3 & -110.3 \\
\hline LLDPE-D40 OS-4 & 5.70 & 4.89 & 10.59 & 5102 & 695 & 58.4 & -107.3 \\
\hline LLDPE-D40 OS-8 & 4.85 & 2.78 & 7.63 & 5258 & 737 & 62.2 & -105.7 \\
\hline LLDPE-D80-1 & 5.80 & 5.45 & 11.25 & 4796 & 617 & 53.0 & -107.8 \\
\hline LLDPE-D80-4 & 5.43 & 4.27 & 9.70 & 5031 & 755 & 59.1 & -104.0 \\
\hline LLDPE-D80-8 & 4.73 & 4.24 & 8.97 & 5627 & 764 & 63.8 & -103.8 \\
\hline
\end{tabular}


and load bearing capability of the material. The addition of BA-D80 produces the highest enhancement in $E^{\prime}$. On the other hand, nanofiller incorporation produces only marginal effect on $E^{\prime \prime}$, without dependence on the BA grade. The glass transition temperature $\left(T_{\mathrm{g}}\right)$, evaluated in correspondence of the $\tan \delta$ peak, was higher for all nanocomposites with respect to unfilled LLDPE, thus reflecting the restriction of the motion of polymer chains induced by the nanofillers incorporation. Moreover, the $T_{\mathrm{g}}$ increase indicates an effective interfacial interaction between the BA nanoparticles and the LLDPE matrix [13]. Comparison plots of the storage modulus $\left(E^{\prime}\right)$ and loss factor $(\tan \delta)$ are reported in Figure $7 \mathrm{a}$ and $7 \mathrm{~b}$, respectively, as a function of temperature for unfilled LLDPE and its nanocomposites containing $4 \mathrm{wt} \%$ BA.

\subsection{Fracture toughness}

The EWF method was applied to characterize the plane stress fracture toughness. At first, the preconditions necessary for the application of the EWF methodology were verified [32]. In particular, the validity criterion verifies that all tests were conducted under plane-stress state. Furthermore, all the specimens exhibited delayed yielding (i.e. the ligament yielding is fully yielded when the crack starts to propagate), with subsequent ductile fracture, showing a large plastic deformation zone surrounding crack tip. Moreover, most specimens manifested evident necking after yielding, in agreement with Equation (3). Since the force - displacement curves of specimens with different ligament lengths were geometrically similar (self-similarity), the

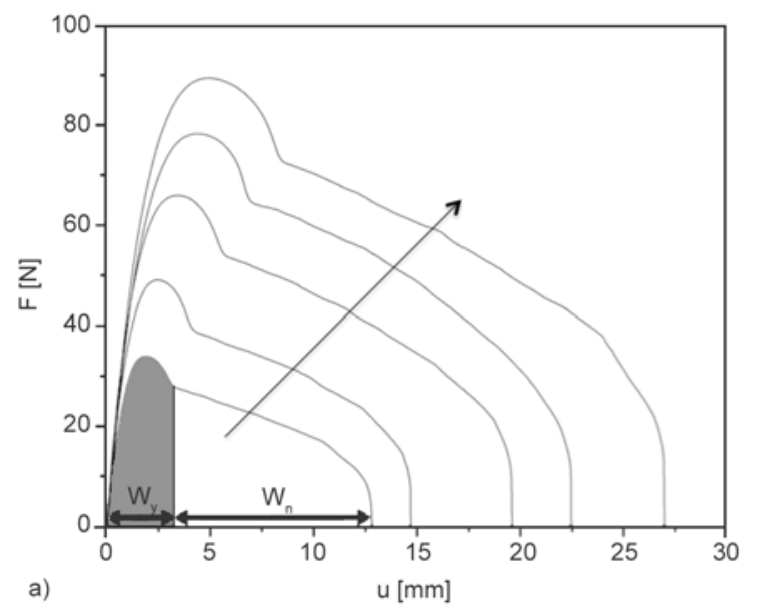

fracture mechanism was probably independent on the ligament length (Figure 8).

Interestingly, in all samples including nanocomposites, the area under the curve after the maximum force is higher than that prior to maximum force, thus indicating slow crack propagation with high energy absorption, typical of ductile materials [33]. The addition of BA nanoparticles to LLDPE did not modify these general features.

The elliptical shape of the stress-whitened zone formed during tensile EWF test performed on LLDPE nanocomposites was similar to that of neat LLDPE with slight variation in the height of the zone. The elliptical shape can be characterised by a shape factor $\beta$, estimated as $\pi \cdot h /(4 L)$, where $h$ is the height of whitened zone while $L$ is the ligament length. The total specific essential work of fracture $\left(w_{\mathrm{e}}\right)$, the specific essential work of fracture at yielding $\left(w_{\mathrm{e}, \mathrm{y}}\right)$ and the specific essential work of fracture for necking $\left(w_{\mathrm{e}, \mathrm{n}}\right)$ were obtained by linear fits and summarized in Table 6. In general, a noticeable improvement of $w_{\mathrm{e}}$ can be observed as the BA content increases for all kinds of BA nanoparticles, whereas $\beta \cdot w_{\mathrm{p}}$ values slightly decrease upon BA addition. These results clearly indicate that BA addition siginficatively toughens the LLDPE matrix [33].

Moreover, partitioned components of the specific essential work of fracture, such as the yieldingrelated component $\left(w_{\mathrm{e}, \mathrm{y}}\right)$ and EWF for neckingrelated component $\left(w_{\mathrm{e}, \mathrm{n}}\right)$, also show an improvement in all nanocomposites when compared to unfilled LLDPE. In particular, the improvement in $w_{\mathrm{e}, \mathrm{y}}$ is probably due to the higher yield stress of nanocomposites with respect to neat LLDPE, while

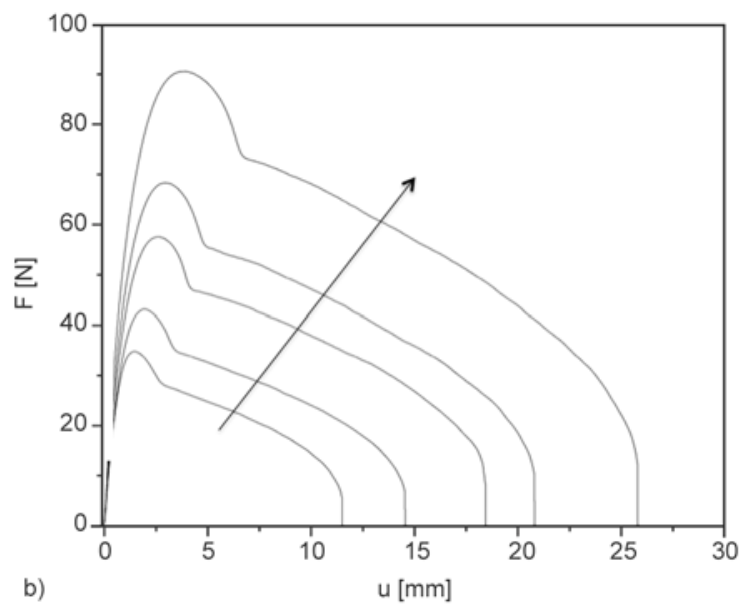

Figure 8. Load-displacement ( $\mathrm{F}-\mathrm{u}$ ) curves of (a) LLDPE and (b) LLDPE-D40-8 nanocomposites. The arrow indicates increasing ligament length. The partitioning between yielding and necking works of fracture is indicated in (a). 
Table 6. Specific EWF properties of LLDPE and relative nanocomposites

\begin{tabular}{|l|c|c|c|c|c|c|c|}
\hline \multicolumn{1}{|c|}{ Sample } & $\begin{array}{c}\mathbf{w}_{\mathbf{e}} \\
{\left[\mathbf{k J J} / \mathbf{m}^{2}\right]}\end{array}$ & $\begin{array}{c}\boldsymbol{\beta} \mathbf{w}_{\mathbf{p}} \\
{\left[\mathbf{M J J} / \mathbf{m}^{3}\right]}\end{array}$ & $\boldsymbol{\beta}$ & $\begin{array}{c}\mathbf{w}_{\mathbf{e}, \mathbf{y}} \\
{\left[\mathbf{k J J} / \mathbf{m}^{2}\right]}\end{array}$ & $\begin{array}{c}\boldsymbol{\beta}^{\prime} \mathbf{w}_{\mathbf{p}, \mathbf{y}} \\
{\left[\mathbf{M J J} / \mathbf{m}^{3}\right]}\end{array}$ & $\begin{array}{c}\mathbf{W}_{\mathbf{e}, \mathbf{n}} \\
{\left[\mathbf{k J} / \mathbf{m}^{2}\right]}\end{array}$ & $\begin{array}{c}\boldsymbol{\beta}^{\prime \prime} \mathbf{w}_{\mathbf{p}, \mathbf{n}} \\
{\left[\mathbf{M J} / \mathbf{m}^{3}\right]}\end{array}$ \\
\hline LLDPE & $26.7 \pm 3.6$ & $\begin{array}{c}12.7 \pm 0.4 \\
(0.983)\end{array}$ & $0.32 \pm 0.04$ & $2.7 \pm 0.3$ & $\begin{array}{c}2.78 \pm 0.03 \\
(0.997)\end{array}$ & $24.2 \pm 3.6$ & $\begin{array}{c}9.9 \pm 0.4 \\
(0.992)\end{array}$ \\
\hline LLDPE-D40-1 & $26.1 \pm 3.3$ & $\begin{array}{c}12.9 \pm 0.4 \\
(0.986)\end{array}$ & $0.27 \pm 0.03$ & $3.1 \pm 0.5$ & $\begin{array}{c}2.72 \pm 0.05 \\
(0.992)\end{array}$ & $23.1 \pm 3.3$ & $\begin{array}{c}10.2 \pm 0.2 \\
(0.990)\end{array}$ \\
\hline LLDPE-D40-4 & $34.1 \pm 3.5$ & $\begin{array}{c}11.8 \pm 0.4 \\
(0.981)\end{array}$ & $0.23 \pm 0.02$ & $3.5 \pm 0.5$ & $\begin{array}{c}2.34 \pm 0.06 \\
(0.988)\end{array}$ & $30.4 \pm 3.5$ & $\begin{array}{c}9.5 \pm 0.4 \\
(0.993)\end{array}$ \\
\hline LLDPE-D40-8 & $42.2 \pm 3.1$ & $\begin{array}{c}11.0 \pm 0.3 \\
(0.983)\end{array}$ & $0.22 \pm 0.02$ & $5.6 \pm 0.5$ & $\begin{array}{c}1.92 \pm 0.06 \\
(0.985)\end{array}$ & $36.5 \pm 3.1$ & $\begin{array}{c}9.1 \pm 0.2 \\
(0.990)\end{array}$ \\
\hline LLDPE-D40 OS-1 & $29.0 \pm 2.0$ & $\begin{array}{c}12.6 \pm 0.2 \\
(0.994)\end{array}$ & $0.28 \pm 0.03$ & $2.8 \pm 0.5$ & $\begin{array}{c}2.80 \pm 0.05 \\
(0.993)\end{array}$ & $26.1 \pm 2.1$ & $\begin{array}{c}9.8 \pm 0.4 \\
(0.991)\end{array}$ \\
\hline LLDPE-D40 OS-4 & $39.1 \pm 2.0$ & $\begin{array}{c}11.6 \pm 0.2 \\
(0.993)\end{array}$ & $0.27 \pm 0.04$ & $4.3 \pm 0.8$ & $\begin{array}{c}2.18 \pm 0.09 \\
(0.970)\end{array}$ & $34.9 \pm 2.1$ & $\begin{array}{c}9.4 \pm 0.3 \\
(0.995)\end{array}$ \\
\hline LLDPE-D40 OS-8 & $42.7 \pm 2.6$ & $\begin{array}{c}10.5 \pm 0.3 \\
(0.986)\end{array}$ & $0.27 \pm 0.03$ & $5.6 \pm 0.3$ & $\begin{array}{c}1.96 \pm 0.04 \\
(0.993)\end{array}$ & $37.0 \pm 2.6$ & $\begin{array}{c}8.5 \pm 0.4 \\
(0.991)\end{array}$ \\
\hline LLDPE-D80-1 & $28.1 \pm 1.3$ & $\begin{array}{c}12.8 \pm 0.2 \\
(0.998)\end{array}$ & $0.27 \pm 0.02$ & $2.8 \pm 0.3$ & $\begin{array}{c}2.80 \pm 0.04 \\
(0.997)\end{array}$ & $25.2 \pm 1.4$ & $\begin{array}{c}10.0 \pm 0.3 \\
(0.993)\end{array}$ \\
\hline LLDPE-D80-4 & $34.0 \pm 2.3$ & $\begin{array}{c}11.9 \pm 0.3 \\
(0.992)\end{array}$ & $0.26 \pm 0.02$ & $4.4 \pm 0.5$ & $\begin{array}{c}2.32 \pm 0.06 \\
(0.988)\end{array}$ & $29.8 \pm 2.4$ & $\begin{array}{c}9.6 \pm 0.2 \\
(0.993)\end{array}$ \\
\hline LLDPE-D80-8 & $43.7 \pm 1.2$ & $\begin{array}{c}10.8 \pm 0.1 \\
(0.997)\end{array}$ & $0.25 \pm 0.02$ & $5.8 \pm 0.4$ & $\begin{array}{c}2.15 \pm 0.04 \\
(0.992)\end{array}$ & $37.8 \pm 1.3$ & $\begin{array}{c}8.7 \pm 0.3 \\
(0.991)\end{array}$ \\
\hline
\end{tabular}

The values in brackets correspond to $R^{2}$ values obtained from the linear regression of the data.

the change in $w_{\mathrm{e}, \mathrm{n}}$ might arise because of an improved crack propagation resistance in nanocomposites [56]. Only marginal differences are appreciable when comparing values of $w_{\mathrm{e}}$ and $\beta \cdot w_{\mathrm{p}}$ in samples filled with different types of BA nanoparticles. On the other hand, the samples LLDPE-D40 OS- $x$ and LLDPE-D80-x show generally higher $w_{\mathrm{e}, \mathrm{y}}$ values due to the higher yield stress measured with respect to that of LLDPE-D40-x samples.

\section{Conclusions}

LLDPE based nanocomposites were prepared through melt compounding and hot pressing using different kinds of BA nanoparticles in order to assess the role of the filler crystallite size and surface treatment on the viscoleastic and fracture response of the material.

In particular, both untreated and octylsilane surface treated BA nanoparticles with crystallite size of $40 \mathrm{~nm}$ were used to produce the nanocomposites. Furthermore, as means of comparison, other samples were produced with untreated BA particles with primary crystallite size of $74 \mathrm{~nm}$. BA particles were finely and homegenously dispersed in LLDPE though in agglomerated form. The nanoscale dispersion of BA was practically not affected by the surface treatment. BA filling did not affect the crystallinity of the nanocomposites though BA acted as nucleant. Presence of BA slightly enhanced the resist- ance to thermo-oxidative degradation of the LLDPE matrix. Incorporation of BA was accompanied with an increase in both tensile modulus and yield strength, and with some reduction in both ultimate tensile strength and elongation at break. The tensile impact energy was prominently improved with increasing amount of BA. Larger crystallite particle size and surface treatment of BA yielded further enhancement in this property. Surprisingly, the melt viscosity was reduced by BA nanofillers.

Short term creep tests showed that creep stability was significatively enhanced by nanofiller incorporation. Concurrently, both storage and loss modulus were increased in all nanocomposites. The planestress specific essential work of fracture showed a considerable increase (up to $64 \%$ ) with the BA content but no significant difference depending on the BA type.

\section{Acknowledgements}

This work was performed in the framework of a bilateral cooperation agreement between Italy and Hungary (HU11MO8).

\section{References}

[1] Dorigato A., Pegoretti A., Penati A.: Linear low-density polyethylene/silica micro- and nanocomposites: Dynamic rheological measurements and modelling. Express Polymer Letters, 4, 115-129 (2010). DOI: 10.3144 /expresspolymlett.2010.16 
[2] Dorigato A., Pegoretti A., Kolařík J.: Nonlinear tensile creep of linear low density polyethylene/fumed silica nanocomposites: Time-strain superposition and creep prediction. Polymer Composites, 31, 1947-1955 (2010). DOI: $10.1002 /$ pc.20993

[3] Fu Y. F., Hu K., Li J., Sun Z. H. Y., Zhang F. Q., Chen D. M.: Influence of nano- $\mathrm{SiO}_{2}$ and carbon fibers on the mechanical properties of POM composites. Mechanics of Composite Materials, 47, 659-662 (2012).

DOI: 10.1007/s11029-011-9245-3

[4] Paul D. R., Robeson L. M.: Polymer nanotechnology: Nanocomposites. Polymer, 49, 3187-3204 (2008). DOI: $10.1016 /$ j.polymer.2008.04.017

[5] Mirzazadeh H., Katbab A. A., Hrymak A. N.: The role of interfacial compatibilization upon the microstructure and electrical conductivity threshold in polypropylene/expanded graphite nanocomposites. Polymers for Advanced Technologies, 22, 863-869 (2011). DOI: $10.1002 /$ pat. 1589

[6] Kalaitzidou K., Fukushima H., Drzal L. T.: Multifunctional polypropylene composites produced by incorporation of exfoliated graphite nanoplatelets. Carbon, 45, 1446-1452 (2007).

DOI: $10.1016 /$ j.carbon.2007.03.029

[7] Baldi F., Bignotti F., Fina A., Tabuani D., Riccò T.: Mechanical characterization of polyhedral oligomeric silsesquioxane/polypropylene blends. Journal of Applied Polymer Science, 105, 935-943 (2007).

DOI: $10.1002 /$ app.26142

[8] Wu J., Mather P. T.: POSS polymers: Physical properties and biomaterials applications. Polymer Reviews, 49, 25-63 (2009).

DOI: $10.1080 / 15583720802656237$

[9] Mehrabzadeh M., Kamal M. R., Quintanar G.: Maleic anhydride grafting onto HDPE by in situ reactive extrusion and its effect on intercalation and mechanical properties of HDPE/clay nanocomposites. Iranian Polymer Journal, 18, 833-842 (2009).

[10] Giannelis E., Krishnamoorti R., Manias E.: Polymersilicate nanocomposites: Model systems for confined polymers and polymer brushes. Advances in Polymer Science, 138, 108-147 (1999).

DOI: $10.1007 / 3-540-69711-x \quad 3$

[11] Li B., Zhong W-H.: Review on polymer/graphite nanoplatelet nanocomposites. Journal of Materials Science, 46, 5595-5614 (2011).

DOI: $10.1007 / \mathrm{s} 10853-011-5572-y$

[12] Kalaitzidou K., Fukushima H., Drzal L. T.: A new compounding method for exfoliated graphite-polypropylene nanocomposites with enhanced flexural properties and lower percolation threshold. Composites Science and Technology, 67, 2045-2051 (2007). DOI: 10.1016/j.compscitech.2006.11.014
[13] Rong M. Z., Zhang M. Q., Pan S. L., Lehmann B., Friedrich K.: Analysis of the interfacial interactions in polypropylene/silica nanocomposites. Polymer International, 53, 176-183 (2004).

DOI: $10.1002 /$ pi. 1307

[14] Zou H., Wu S., Shen J.: Polymer/silica nanocomposites: Preparation, characterization, properties, and applications. Chemical Reviews, 108, 3893-3957 (2008). DOI: 10.1021/cr068035q

[15] Zhou R-J., Burkhart T.: Polypropylene/ $\mathrm{SiO}_{2}$ nanocomposites filled with different nanosilicas: Thermal and mechanical properties, morphology and interphase characterization. Journal of Materials Science, 46, 12281238 (2011).

DOI: $10.1007 / \mathrm{s} 10853-010-4901-\mathrm{x}$

[16] Bikiaris D. N., Vassiliou A., Pavlidou E., Karayannidis G. P.: Compatibilisation effect of PP-g-MA copolymer on $\mathrm{iPP} / \mathrm{SiO}_{2}$ nanocomposites prepared by melt mixing. European Polymer Journal, 41, 1965-1978 (2005). DOI: $10.1016 /$ j.eurpolymj.2005.03.008

[17] Lin O., Mohd Ishak Z., Akil H. M.: Preparation and properties of nanosilica-filled polypropylene composites with PP-methyl POSS as compatibiliser. Materials and Design, 30, 748-751 (2009).

DOI: $10.1016 /$ j.matdes.2008.05.007

[18] Liu S-P., Ying J-R., Zhou X-P., Xie X-L., Mai Y-W.: Dispersion, thermal and mechanical properties of polypropylene/magnesium hydroxide nanocomposites compatibilized by SEBS- $g$-MA. Composites Science and Technology, 69, 1873-1879 (2009).

DOI: $10.1016 /$ j.compscitech.2009.04.004

[19] Mohebby B., Fallah-Moghadam P., Ghotbifar A. R., Kazemi-Najafi S.: Influence of maleic-anhydride-polypropylene (MAPP) on wettability of polypropylene/ wood flour/glass fiber hybrid composites. Journal of Agricultural Science and Technology, 13, 877-884 (2011).

[20] Kontou E., Niaounakis M.: Thermo-mechanical properties of LLDPE/SiO $\mathrm{S}_{2}$ nanocomposites. Polymer, 47, 1267-1280 (2006).

DOI: 10.1016/j.polymer.2005.12.039

[21] Dorigato A., Dzenis Y., Pegoretti A.: Nanofiller aggregation as reinforcing mechanism in nanocomposites. Procedia Engineering, 10, 894-899 (2011). DOI: $10.1016 /$ j.proeng.2011.04.147

[22] Dorigato A., Pegoretti A.: Fracture behaviour of linear low density polyethylene - fumed silica nanocomposites. Engineering Fracture Mechanics, 79, 213-224 (2012).

DOI: 10.1016/j.engfracmech.2011.10.014

[23] Pedrazzoli D., Pegoretti A.: Silica nanoparticles as coupling agents for polypropylene/glass composites. Composites Science and Technology, 76, 77-83 (2013). DOI: 10.1016/j.compscitech.2012.12.016 
[24] Halbach T. S., Mülhaupt R.: Boehmite-based polyethylene nanocomposites prepared by in-situ polymerization. Polymer, 49, 867-876 (2008).

DOI: $10.1016 /$ j.polymer.2007.12.007

[25] Halbach T. S., Thomann Y., Mülhaupt R.: Boehmite nanorod-reinforced-polyethylenes and ethylene/1octene thermoplastic elastomer nanocomposites prepared by in situ olefin polymerization and melt compounding. Journal of Polymer Science Part A: Polymer Chemistry, 46, 2755-2765 (2008).

DOI: $10.1002 /$ pola.22608

[26] Khumalo V. M., Karger-Kocsis J., Thomann R.: Polyethylene/synthetic boehmite alumina nanocomposites: Structure, thermal and rheological properties. Express Polymer Letters, 4, 264-274 (2010). DOI: $10.3144 /$ expresspolymlett.2010.34

[27] Streller R. C., Thomann R., Torno O., Mülhaupt R.: Isotactic poly(propylene) nanocomposites based upon boehmite nanofillers. Macromolecular Materials and Engineering, 293, 218-227 (2008).

DOI: $10.1002 /$ mame.200700354

[28] Bocchini S., Morlat-Thérias S., Gardette J-L., Camino G.: Influence of nanodispersed boehmite on polypropylene photooxidation. Polymer Degradation and Stability, 92, 1847-1856 (2007).

DOI: $10.1016 /$ j.polymdegradstab.2007.07.002

[29] Siengchin S., Karger-Kocsis J.: Structure and creep response of toughened and nanoreinforced polyamides produced via the latex route: Effect of nanofiller type. Composites Science and Technology, 69, 677-683 (2009).

DOI: 10.1016/j.compscitech.2009.01.003

[30] Siengchin S., Karger-Kocsis J., Apostolov A. A., Thomann R.: Polystyrene-fluorohectorite nanocomposites prepared by melt mixing with and without latex precompounding: Structure and mechanical properties. Journal of Applied Polymer Science, 106, 248254 (2007).

DOI: 10.1002/app.26474

[31] Brandrup J., Immergut E. H., Grulke E. A.: Polymer handbook. Wiley, New York (1999).

[32] Williams J. G., Rink M.: The standardisation of the EWF test. Engineering Fracture Mechanics, 74, 1009 1017 (2007). DOI: 10.1016/j.engfracmech.2006.12.017

[33] Bárány T., Czigány T., Karger-Kocsis J.: Application of the essential work of fracture (EWF) concept for polymers, related blends and composites: A review. Progress in Polymer Science, 35, 1257-1287 (2010). DOI: 10.1016/j.progpolymsci.2010.07.001

[34] Tuba F., Khumalo V. M., Karger-Kocsis J.: Essential work of fracture of poly( $\varepsilon$-caprolactone)/boehmite alumina nanocomposites: Effect of surface coating. Journal of Applied Polymer Science, in press (2013). DOI: 10.1002/APP.39004
[35] Brostow W., Datashvili T., Huang B., Too J.: Tensile properties of LDPE + boehmite composites. Polymer Composites, 30, 760-767 (2009).

DOI: $10.1002 / p c .20610$

[36] Droval G., Aranberri I., Ballestero J., Verelst M., Dexpert-Ghys J.: Synthesis and characterization of thermoplastic composites filled with $\gamma$-boehmite for fire resistance. Fire and Materials, 35, 491-504 (2011).

DOI: $10.1002 /$ fam.1068

[37] Azároff L. V.: Elements of X-ray crystallography. New York, McGraw-Hill (1968).

[38] Kiss A. B., Keresztury G., Farkas L.: Raman and i.r. spectra and structure of boehmite $(\gamma-\mathrm{AlOOH})$. Evidence for the recently discarded $D^{17}$ h space group. Spectrochimica Acta Part A: Molecular Spectroscopy, 36, 653-658 (1980). DOI: $10.1016 / 0584-8539(80) 80024-9$

[39] Brostow W., Datashvili T.: Chemical modification and characterization of boehmite nanoparticles. Chemistry and Chemical Technology, 2, 27-32 (2008).

[40] Abdel-Goad M., Pötschke P.: Rheological characterization of melt processed polycarbonate-multiwalled carbon nanotube composites. Journal of Non-Newtonian Fluid Mechanics, 128, 2-6 (2005).

DOI: $10.1016 /$ j.jnnfm.2005.01.008

[41] Cassagnau P.: Melt rheology of organoclay and fumed silica nanocomposites. Polymer, 49, 2183-2196 (2008). DOI: $10.1016 /$ j.polymer.2007.12.035

[42] Ganß M., Satapathy B. K., Thunga M., Weidisch R., Pötschke P., Jehnichen D.: Structural interpretations of deformation and fracture behavior of polypropylene/ multi-walled carbon nanotube composites. Acta Materialia, 56, 2247-2261 (2008).

DOI: $10.1016 /$ j.actamat.2008.01.010

[43] Renger C., Kuschel P., Kristoffersson A., Clauss B., Oppermann W., Sigmund W.: Rheology studies on highly filled nano-zirconia suspensions. Journal of the European Ceramic Society, 27, 2361-2367 (2007). DOI: $10.1016 /$ j.jeurceramsoc.2006.08.022

[44] Sarvestani A. S.: Modeling the solid-like behavior of entangled polymer nanocomposites at low frequency regimes. European Polymer Journal, 44, 263-269 (2008).

DOI: $10.1016 /$ j.eurpolymj.2007.11.023

[45] Sepehr M., Utracki L. A., Zheng X., Wilkie C. A.: Polystyrenes with macro-intercalated organoclay. Part II. Rheology and mechanical performance. Polymer, 46, 11569-11581 (2005).

DOI: 10.1016/j.polymer.2005.10.032

[46] Wu D., Wu L., Wu L., Zhang M.: Rheology and thermal stability of polylactide/clay nanocomposites. Polymer Degradation and Stability, 91, 3149-3155 (2006). DOI: $10.1016 /$ j.polymdegradstab.2006.07.021

[47] Blaszczak P., Brostow W., Datashvili T., Lobland H. E. H.: Rheology of low-density polyethylene + Boehmite composites. Polymer Composites, 31, 1909-1913 (2010).

DOI: $10.1002 /$ pc.20987 
[48] Dorigato A., Dzenis Y., Pegoretti A.: Filler aggregation as a reinforcement mechanism in polymer nanocomposites. Mechanics of Materials, 61, 79-90 (2013). DOI: 10.1016/j.mechmat.2013.02.004

[49] Bansal N. P.: Handbook of ceramic composites. New York, Kluwer (2005).

[50] Dzenis Y.: Effect of aggregation of a dispersed rigid filler on the elastic characteristics of a polymer composite. Mechanics of Composite Materials, 22, 12-19 (1986). DOI: $10.1007 / \mathrm{BF} 00606002$

[51] Khumalo V. M., Karger-Kocsis J., Thomann R.: Polyethylene/synthetic boehmite alumina nanocomposites: Structure, mechanical, and perforation impact properties. Journal of Materials Science, 46, 422-428 (2010). DOI: $10.1007 / \mathrm{s} 10853-010-4882-9$

[52] Rong M. Z., Zhang M. Q., Zheng Y. X., Zeng H. M., Walter R., Friedrich K.: Irradiation graft polymerization on nano-inorganic particles: An effective means to design polymer-based nanocomposites. Journal of Materials Science Letters, 19, 1159-1161 (2000). DOI: 10.1023/A:1006711326705
[53] Rong M. Z., Zhang M. Q., Zheng Y. X., Zeng H. M., Walter R., Friedrich K.: Structure-property relationships of irradiation grafted nano-inorganic particle filled polypropylene composites. Polymer, 42, 167183 (2001). DOI: $10.1016 / \mathrm{S} 0032-3861(00) 00325-6$

[54] Wu C. L., Zhang M. Q., Rong M. Z., Friedrich K.: Tensile performance improvement of low nanoparticles filled-polypropylene composites. Composites Science and Technology, 62, 1327-1340 (2002). DOI: 10.1016/S0266-3538(02)00079-9

[55] Bondioli F., Dorigato A., Fabbri P., Messori M., Pegoretti A.: Improving the creep stability of highdensity polyethylene with acicular titania nanoparticles. Journal of Applied Polymer Science, 112, 10451055 (2009). DOI: $10.1002 / a p p .29472$

[56] Yang W., Xie B-H., Shi W., Li Z-M., Liu Z-Y., Chen J., Yang M-B.: Essential work of fracture evaluation of fracture behavior of glass bead filled linear low-density polyethylene. Journal of Applied Polymer Science, 99, 1781-1787 (2006).

DOI: $10.1002 /$ app. 22708 